\title{
Erratum to: Intercropping green manure crops-effects on rooting patterns
}

\author{
Kae Miyazawa • Toshifumi Murakami • \\ Masae Takeda • Tohru Murayama
}

Published online: 3 August 2010

(C) Springer Science+Business Media B.V. 2010

Erratum to: Plant Soil (2010) 331:231-239

DOI 10.1007/s11104-009-0248-y

Owing to an error on the authors' part, the y-axis unit of Fig. 6 was printed incorrectly. The correct unit is $\mathrm{g} / 0.125 \mathrm{~m}^{2}$.

Responsible Editor: Martin Weih.

The online version of the original article can be found at http:// dx.doi.org/10.1007/s11104-009-0248-y.

K. Miyazawa $(\bowtie) \cdot$ T. Murakami $\cdot$ M. Takeda $•$

T. Murayama

Cover Crop Research Team, National Agricultural,

Research Center for Tohoku Region,

50 Harajuku-minami,

Fukushima, Fukushima 960-2156, Japan

e-mail: kae@affrc.go.jp 